\title{
POSTNATAL STEROIDS FOR THE TREATMENT OF SEVERE CYANOTIC SPELLS IN MECHANICALLY VENTILATED PRETERM INFANTS
}

\author{
S.A. Prins, V.E.H.J. Smits-Wintjens, F.J. Walther, E. Lopriore, A.B. Te Pas \\ Neonatology, Leiden University Medical Center, Leiden, The Netherlands
}

Background and aims: Bronchopulmonary dysplasia spells are defined as spells with intermittent cessation of airflow in prolonged mechanically ventilated very preterm infants leading to desaturation and bradycardia. However, similar spells occurring in the first two weeks after birth have not been described before.

Methods: We present a case series of very preterm infants with refractory cyanotic spells and describe the effect of treatment with steroids.

Results: Between June 2010 and January 201123 infants $<27$ weeks of gestation were admitted to our neonatal unit, of which 6 infants (mean (SD) gestational age 24.5 (0.5) weeks, birth weight 767 (86) grams suffered from refractory cyanotic spells. These infants initially received nasal CPAP without extra oxygen but due to spells intubation followed in the first week of life. During mechanical ventilation spells continued ( $>10$ incidents/day) and we observed cessation of airflow, low tidal volumes, desaturation $<50 \%$ and bradycardia $<80 \mathrm{bpm}$ (figure 1). The cyanotic spells were refractory to caffeine, theophylline, doxapram, phenobarbital, high frequency oscillation and nitric oxide. The spells decreased in severity and frequency soon after starting dexamethason after the first week of life. Successful ectubation followed in all patients within 3 days.

Conclusion: Future studies are needed, but early cyanotic spells occurring in very preterm infants seem to respond well to postnatal steroids.

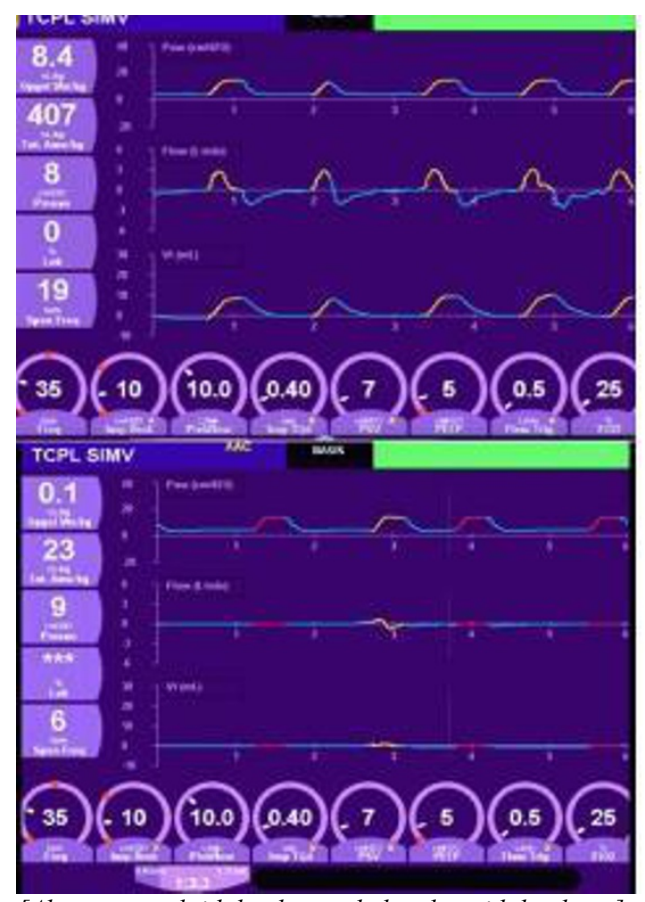

[Above normal tidal volumes, below low tidal volume] 